
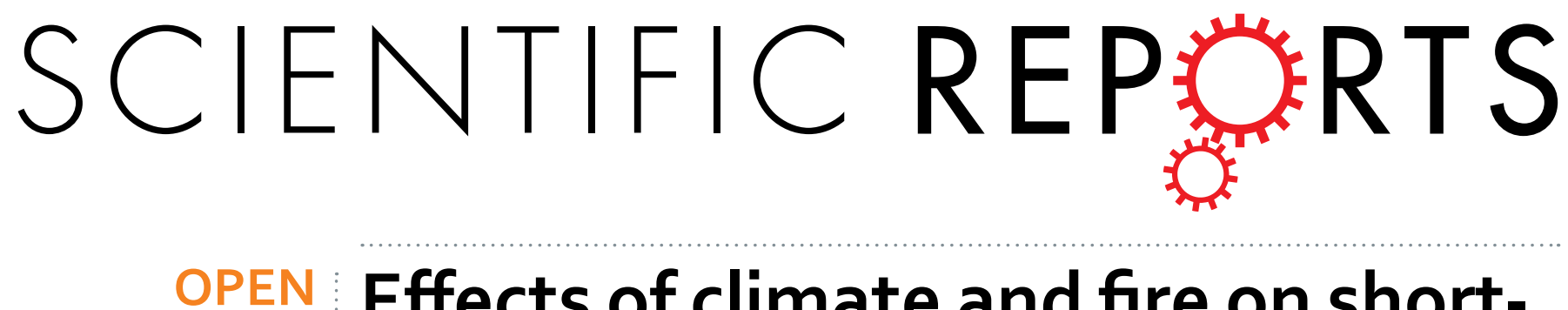

\title{
Effects of climate and fire on short- term vegetation recovery in the boreal larch forests of Northeastern
}

Received: 29 June 2016

Accepted: 01 November 2016

Published: 18 November 2016
China

Zhihua Liu

Understanding the influence of climate variability and fire characteristics in shaping postfire vegetation recovery will help to predict future ecosystem trajectories in boreal forests. In this study, I asked: (1) which remotely-sensed vegetation index (VI) is a good proxy for vegetation recovery? and (2) what are the relative influences of climate and fire in controlling postfire vegetation recovery in a Siberian larch forest, a globally important but poorly understood ecosystem type? Analysis showed that the shortwave infrared (SWIR) VI is a good indicator of postfire vegetation recovery in boreal larch forests. A boosted regression tree analysis showed that postfire recovery was collectively controlled by processes that controlled seed availability, as well as by site conditions and climate variability. Fire severity and its spatial variability played a dominant role in determining vegetation recovery, indicating seed availability as the primary mechanism affecting postfire forest resilience. Environmental and immediate postfire climatic conditions appear to be less important, but interact strongly with fire severity to influence postfire recovery. If future warming and fire regimes manifest as expected in this region, seed limitation and climate-induced regeneration failure will become more prevalent and severe, which may cause forests to shift to alternative stable states.

Boreal forests comprise one third of the global forested area, and regulate the climate system via the carbon cycle and land-atmosphere energy exchange ${ }^{1-3}$. Recent unprecedented rates of climate warming and an associated increase in wildfire frequency, severity and size $e^{4,5}$ have the potential to push the boreal forest ecosystem across a threshold beyond which forest dieback, forest compositional change, and loss of carbon sequestration capacity may occur ${ }^{6-8}$. Accumulating evidence suggests that initial forest conditions and disturbance legacy effects can play key roles in determining postfire community composition and function in boreal forests ${ }^{9}$, and interactions among climate variability, historical contingency, and vegetation disturbance responses may cause threshold responses and generate unexpected ecosystem trajectories in the biome ${ }^{10}$. As boreal forests are increasingly affected by intensifying fire regimes and a greater degree of climatic variability, an improved understanding of the mechanisms that determine vegetation recovery following disturbance is critical for providing insight into the potential for novel ecological trajectories ${ }^{11}$.

Observational and experimental studies have found that fire interacts with tree species' fire-adaptation strategies, strongly affects seed availability and site condition, and thus plays a dominant role in determining tree recruitment in the boreal forest ecosystem ${ }^{12,13}$. In fire "embracer"-dominated forests, such as those dominated by Picea mariana, Pinus contorta, and Pinus banksiana, fires are typically of intermediate frequency and high severity. However, forests can generally regenerate locally from seeds stored in serotinous cones ${ }^{9,14}$. As a result, site conditions (e.g., organic layer depth) play a major role in determining the postfire successional trajectory of forests due to the different regeneration abilities of deciduous hardwoods and conifers ${ }^{9,15}$. In fire "avoider"-dominated forests, where species such as Abies sibirica, Abies nephrolepis, Picea abies and Picea obovata are dominant, fire is infrequent and stand-replacing, and trees rarely survive fires. These forests rely on seed dispersal from unburned trees to regenerate. Therefore, seed limitation plays a major role in determining postfire successional trajectories via the different dispersal abilities of deciduous hardwoods and conifers ${ }^{13}$. In fire "resister"-dominated forests,

Key Laboratory of Forest Ecology and Management, Institute of Applied Ecology, Chinese Academy of Sciences, Shenyang, 110164, China. Correspondence and requests for materials should be addressed to Z.L. (email: liuzh@ iae.ac.cn) 
such those where Pinus sylvestris and Larix spp. are dominant, fire is frequent and of low to medium intensity, and trees usually survive fire due to their thick bark. Although "resisters" dominate the light taiga of Siberia and cover about $20 \%$ of global boreal forests, little research has been conducted to investigate the mechanisms that determine postfire vegetation recovery.

Climate variability is another major determinant of postfire vegetation recovery ${ }^{16}$. Climate affects vegetation recovery directly through its influence on plant demography (i.e., colonization and establishment) and indirectly through its influence on fire regime. Plants depend on favorable climatic conditions to regenerate and survive. Plant establishment and growth are generally higher under favorable postfire climatic conditions, such as conditions with higher precipitation and moisture availability ${ }^{17,18}$. Fire regimes are largely climate-driven, and are expected to intensify with warmer and drier climates in boreal forests ${ }^{1}$. As a result, altered seed availability and site conditions under intensified fire regimes may slow forest recovery ${ }^{19,20}$, or change successional trajectories $^{9}$. Furthermore, homogenization of fire severity within individual fires may alter vegetation legacies and burned patch configurations, and thus change seed dispersal patterns on the landscape ${ }^{11,14,16}$. Once established, the longer-term vegetation successional trajectories depend on initial vegetation density and composition ${ }^{21-23}$ and favorable climate conditions. Therefore, vegetation recovery is determined by multiple interacting factors ranging from fire characteristics, climate variability, and plant regeneration strategies, to environmental filters at variable spatial and temporal scales. Disentangling the relative influences of climate variability and fire characteristics, among other environmental filters, is challenging.

Previous studies have made substantial contributions to our understanding of the influence of site conditions and seed availability in shaping postfire successional trajectories. However, most studies are limited in space and time, and therefore have limited abilities to disentangle the effects of multiple interacting factors on vegetation recovery and generalize these at large scales. In contrast, satellite observations of postfire studies can potentially overcome these limitations through spatially and spectrally consistent monitoring of fire characteristics and fire effects on vegetation over large regions. Normalized Difference Vegetation Index (NDVI) is the most commonly vegetation index to monitor postfire vegetation recovery trajectories due to its sensitivity to vegetation chlorophyll content or "greenness" 24,25 . However, NDVI, like many other vegetation indices, is also limited by a number of issues, including saturation in closed canopies, and sensitivities to atmospheric aerosols and soil background ${ }^{26}$. Recent remote sensing analyses have shown that short-wave infrared (SWIR)-based vegetation indices are sensitive to vegetation water content and canopy structure in boreal Canadian ${ }^{27}$ and Siberian forests ${ }^{28}$. However, the potential of SWIR-based vegetation indices for measuring vegetation recovery has not yet been fully explored ${ }^{29}$.

The objective of this analysis is to explore the potential roles of climate variability and fire characteristics in controlling the short-term ( $\sim 5$ years) vegetation recovery in a "resister"-dominated Dahurian Larch (Larix gmelini) forest in a climate- and fire-sensitive region of Northeastern China. As fire "resisters", Larch trees survive low to medium intensity fires, and provide abundant seed source for forest recovery. Consequently, the Larch forests are unlikely to be seed-limited except following very severe fires with few surviving seed sources ${ }^{30}$. The study region is in the transition zone between boreal and temperate along a temperature gradient, and between woodland and grassland zones along a moisture gradient (see Study area). Climate variability has an important role in determining vegetation composition and dynamics ${ }^{31}$. Therefore, the central hypothesis is that climate variability is the primary determinant of postfire vegetation recovery in this region. In this study, this hypothesis is tested by investigating postfire vegetation recovery with varying climatic conditions and fire characteristics across a large spatiotemporal scale using a remote sensing approach. The specific research questions are (1) to determine the best vegetation index for measuring postfire vegetation recovery, and (2) to understand the relative influences of climate and fire characteristics on postfire vegetation recovery in a Siberian Larch forest. This study will elucidate the role of changing fire regimes and climate in shaping vegetation recovery and contribute to the understanding of fire-vegetation-climate interactions in a globally important, but poorly-understood boreal forest.

\section{Methods}

Study area. The Great Xing'an Mountains are located in the boreal-temperate forest transition zone of Northeastern China, and encompass approximately $8.46 \times 10^{4} \mathrm{~km}^{2}$ (Fig. 1). The area has a cold, continental climate, with average annual temperatures declining from $1{ }^{\circ} \mathrm{C}$ at the southern extreme to $-6^{\circ} \mathrm{C}$ at the northern extreme, and precipitation declining from $442 \mathrm{~mm}$ in the South to $240 \mathrm{~mm}$ in the North. The vegetation of this area is representative of cool temperate coniferous forests, forming the southern extension of the eastern Siberian Larch forests. The forests mainly comprise of Dahurian Larch, with a few other locally abundant species, such as Pine (Pinus sylvestris var. mongolica), Spruce (Picea koraiensis), Birch (Betula platyphylla), two species of Aspen (Populus davidiana, Populus suaveolens), Willow (Chosenia arbutifolia), and a shrub species, Pinus pumila. The historical fire regime of this eastern Siberian boreal forest included low intensity surface fires mixed with infrequent stand-replacing fires, with fire return intervals ranging from 30 to 120 years ${ }^{32}$. However, intensive forest management and fire suppression since the 1950s have altered fire regimes in this region, and current fires have been infrequent, but more intense, with a fire return interval of more than 500 years $^{33}$. Understory species composition is closely related to topographic position in both mature and early post-fire successional stages ${ }^{34}$. Welldrained, south-facing slopes are generally warm and dry, and have mostly herbaceous species and a few shrub species, such as Epilobium angustifolium L., Rubus sachalinensis var. sachalinensis, Rhododendron dauricum L. These slopes experience fires of relatively higher frequency and lower intensity. North slopes and terraces are generally wet and cool, and dominated by two shrub species, Ledum palustre and Vaccinium uliginosum (up to $0.4 \mathrm{~m}$ in height), supporting relatively infrequent, high intensity fires due to more contiguous and high-loading fuels ${ }^{35}$. Postfire tree seedling consists mainly larch and birch, and the understory species contribute more to early vegetation recovery in higher severity burned patches ${ }^{20}$. 


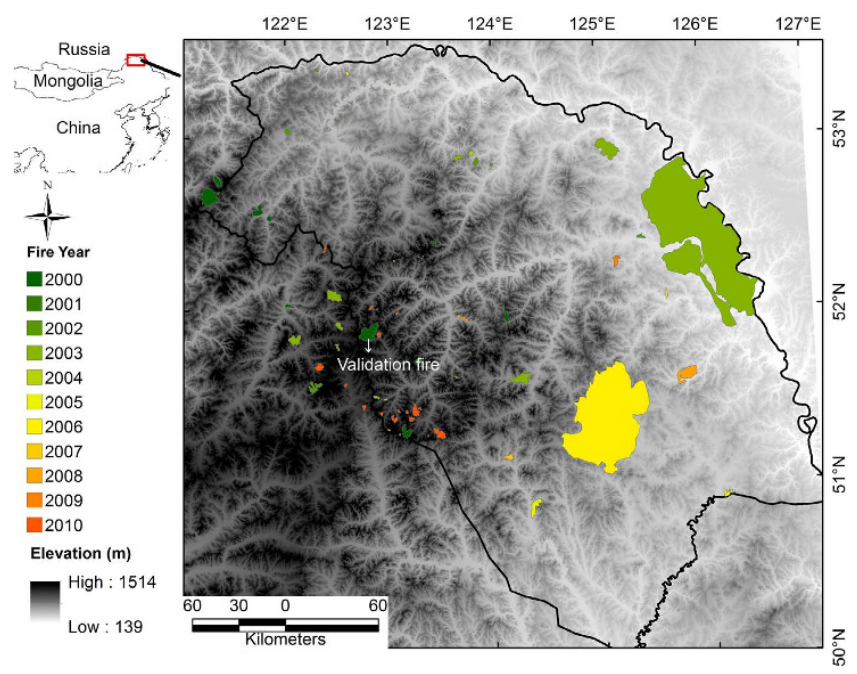

Figure 1. Study area with burned patches (2000-2010), and digital elevation model (DEM) map. The DEM was download from SRTM (Shuttle Radar Topography Mission) website (http://www2.jpl.nasa.gov/srtm/). Burned patches were manually digitized based on reported fire information and Landsat images (this study). The burned patch used for field measurement was also indicated. The map was produced in ArcGIS 10.3 (http:// www.esri.com/).

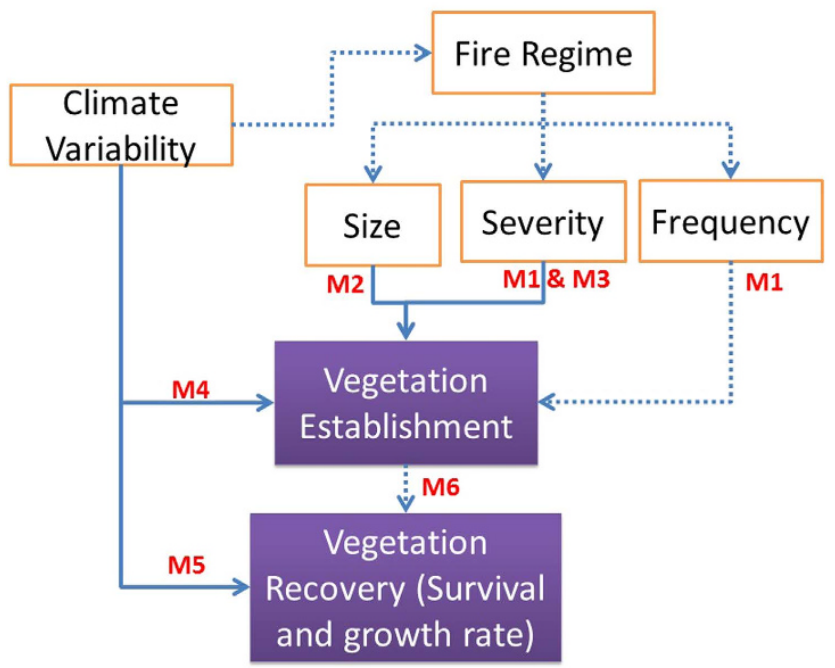

Figure 2. Hypothetical relationship among climate variability, fire regime, and postfire vegetation recovery in boreal forest ecosystems (see text for details). Solid lines indicated mechanisms that were tested in current analysis.

Conceptual model and variable selection. The effects of climate variability and fire characteristics on vegetation recovery in boreal forests relates to a series of mechanisms that control seed supply, seed delivery, seed regeneration, and seedling establishment and growth (Fig. 2; M1-M6) ${ }^{36}$. First, seed supply (M1) is related to fire frequency which alters seed production depending on the balance between fire return intervals and the time required for trees to reach maturity. Seed supply is also related to fire severity, which determines seed survival ${ }^{37}$. Second, seed delivery (M2) relates to the patch size of high-severity burns and to the seed dispersal abilities of different species ${ }^{38}$. Third, seed regeneration is determined by both seedbed environment (M3) and immediate postfire climatic conditions (M4). Fire severity modifies site conditions which may favor some tree species more than others, resulting in changes in postfire species composition. For example, increasing fire severity promotes the recruitment of deciduous tree species and decreases the relative abundance of black spruce immediately following fire in interior Alaska ${ }^{9}$. Postfire seedling recruitment typically occurs during a short postfire climatic window, and therefore immediate postfire climate conditions control seed regeneration and seedling survival. For example, drier years following fires have been found to suppress the seed regeneration in subalpine and montane forests in western North America ${ }^{16}$. Finally, vegetation recovery also depends on longer-term climate suitability (M5), and successional pathways (M6). All else being equal, favorable climatic conditions generally promote survival and 


\begin{tabular}{|c|c|c|c|}
\hline Variables & Descriptions and related mechanisms in Fig. 2. & Hypothetical relationship with vegetation recovery & Range (median) \\
\hline Year + 5 NDWI (unitless) & $\begin{array}{l}\text { A proxy for postfire vegetation recovery status, } \\
\text { 5-year postfire }\end{array}$ & & $-0.43-0.53(0.20)$ \\
\hline RdNBR (unitless) & $\begin{array}{l}\text { A proxy for fire severity, Relative dNBR (M1 \& } \\
\text { M3). }\end{array}$ & $\begin{array}{l}\text { Negatively, higher fire severity consumes more } \\
\text { seed stored in soil and canopy and reduces seed } \\
\text { availability }{ }^{19,20}\end{array}$ & $0-1.48(0.36)$ \\
\hline RdNBR_var (unitless) & $\begin{array}{l}\text { A proxy for spatial variability of fire severity, } \\
\text { standard deviation of RdNBR within a } 120 \mathrm{~m} \\
\text { radius (M1) }\end{array}$ & $\begin{array}{l}\text { Positively, higher spatial variability of fire severity } \\
\text { increases the chance of tree survival and provides } \\
\text { more seed within burned patches }{ }^{11}\end{array}$ & $0.00117-0.334(0.0455)$ \\
\hline $\mathrm{D} 2 \mathrm{~B}(\mathrm{~m})$ & $\begin{array}{l}\text { A proxy for seed dispersal distance, distance to } \\
\text { nearest unburned forest (M2) }\end{array}$ & $\begin{array}{l}\text { Negatively, the probability of seed reach to a site } \\
\text { decreases exponentially with distance to seed sources }\end{array}$ & 0-9999 (2790) \\
\hline SHP_IDX (unitless) & $\begin{array}{l}\text { A proxy for fire patch characteristics, shape index } \\
\text { for each fire (M2). }\end{array}$ & $\begin{array}{l}\text { Positively, higher patch complexity increase the } \\
\text { probability of seed reach to a site from the seed } \\
\text { source }\end{array}$ & $1-2.79(1.71)$ \\
\hline TAno_Summer + 0 (degree) & $\begin{array}{l}\text { Summer temperature anomaly for the fire year } \\
\text { (M4). }\end{array}$ & $\begin{array}{l}\text { Unimodal, plants regenerate and grow better at the } \\
\text { intermediate level of temperature }{ }^{17}\end{array}$ & $-0.88-1.48(-0.83)$ \\
\hline TAno_Winter + 0 (degree) & $\begin{array}{l}\text { Winter temperature anomaly for the fire year } \\
\text { (M4). }\end{array}$ & The same as TAno_Summer +0 & $-4.41-2.88(0.39)$ \\
\hline TAno_Summer + 1 (degree) & $\begin{array}{l}\text { Summer temperature anomaly one year after } \\
\text { fire (M4). }\end{array}$ & The same as TAno_Summer +0 & $-0.30-0.99(0.30)$ \\
\hline TAno_Summer + 1-5 (degree) & $\begin{array}{l}\text { Average summer temperature anomaly from one } \\
\text { to five years after fire (M5). }\end{array}$ & The same as TAno_Summer +0 & $-0.039-0.59(-0.0089)$ \\
\hline PAno_Summer $+0(\mathrm{~mm})$ & $\begin{array}{l}\text { Summer precipitation anomaly for the fire year } \\
\text { (M4). }\end{array}$ & $\begin{array}{l}\text { Positive, plants regenerate and grow better at higher } \\
\text { moisture availability }\end{array}$ & $-45.41-58.95(36.97)$ \\
\hline PAno_Winter $+0(\mathrm{~mm})$ & $\begin{array}{l}\text { Winter precipitation anomaly for the fire year } \\
\text { (M4). }\end{array}$ & The same as PAno_Summer +0 & $-1.94-4.43(0.55)$ \\
\hline PAno_Summer + $1(\mathrm{~mm})$ & $\begin{array}{l}\text { Summer precipitation anomaly one year after } \\
\text { fire (M4). }\end{array}$ & The same as PAno_Summer +0 & $-45.41-21.08(-11.54)$ \\
\hline PAno_Summer + 1-5 (mm) & $\begin{array}{l}\text { Average Summer precipitation anomaly from one } \\
\text { to five years after fire (M5) }\end{array}$ & The same as PAno_Summer +0 & $-21.63-9.83(-7.16)$ \\
\hline $\operatorname{DEM}(\mathrm{m})$ & Elevation & $\begin{array}{l}\text { Negative, higher elevation is often associated with } \\
\text { higher fire severity and lower soil moisture, and } \\
\text { decreases forest recovery }\end{array}$ & $177-1297(416)$ \\
\hline Slope (degree) & Slope & $\begin{array}{l}\text { Negative, steeper slope has thinner soil layer and } \\
\text { lower soil moisture, and decreases forest recovery }{ }^{19,20}\end{array}$ & $0.000-17.3(3.168)$ \\
\hline Potential radiation (unitless) & A proxy for solar radiation and soil moisture & $\begin{array}{l}\text { Negative, higher solar radiation decrease soil } \\
\text { moisture, and decreases forest recovery }\end{array}$ & $-1-1(-0.099)$ \\
\hline
\end{tabular}

Table 1. predictors used to quantify the influence of climate, fire, and topography on postfire vegetation recovery in the boosted regression tree model.

growth rates. The ecosystem successional trajectory is also determined by postfire species composition and density ${ }^{11,36}$. These climate and fire mechanisms were also modulated by biophysical environment of burned patches. All these mechanisms and related variable selection was listed in Table 1.

Dataset. Landsat data. Thirty-meter resolution Landsat data were used to characterize postfire vegetation recovery between 1999 and 2015. Landsat images were mostly selected from the peak growing season (July and August) and acquired by the ETM + sensor with cloud cover $<20 \%$ to minimize the potential influence of phenology, sensors, and clouds on vegetation indices ${ }^{39}$. If no suitable ETM+ image was found for a particular fire, ETM+ images were acquired between June 15 and 30 or July and August images were acquired from the TM sensor. Of the 94 images used in this analysis, 84 images were from the peak growing season, and 71 were from the ETM+ sensor (Fig. 3). Landsat L1T data acquired from USGS GLOVIS portal (http://glovis.usgs.gov/) has been radiometric and geometric corrected and were converted to top-of-atmosphere reflectance and then atmospherically corrected to surface reflectance using the Landsat Ecosystem Disturbance Adaptive Processing System (LEDAPS $)^{40}$. The data gap caused by the Scan Line Corrector failure in each ETM+ images after May 31, 2003 was removed from the analysis. Clouds and cloud shadows were masked out using an object-based approach called the F-mask algorithm ${ }^{41}$. The potential influences of topography and sun-sensor geometry (e.g., BRDF effects) on surface reflectance were relatively minor and were not corrected ${ }^{42}$.

Fire scars. Historical burned patches between 2000 and 2010 were manually digitized based on fire ignition locations and year ${ }^{5}$ using delta Normalized Burn Ratio (dNBR) images. The dNBR is widely used in mapping burned patches and severity in various forest ecosystems $\mathrm{s}^{43,44}$, and was proven to be applicable to our study area by comparing dNBR values with field-based burn severity data ${ }^{45}$. The dNBR images were calculated by subtracting NBR images one year before the fire from NBR images in the fire year, as fires usually burned prior to the peak growing season. Large positive dNBR values indicate disturbance events. The NBR is computed as:

$$
N B R=\frac{\rho N I R-\rho S W I R 2}{\rho N I R+\rho S W I R 2}
$$




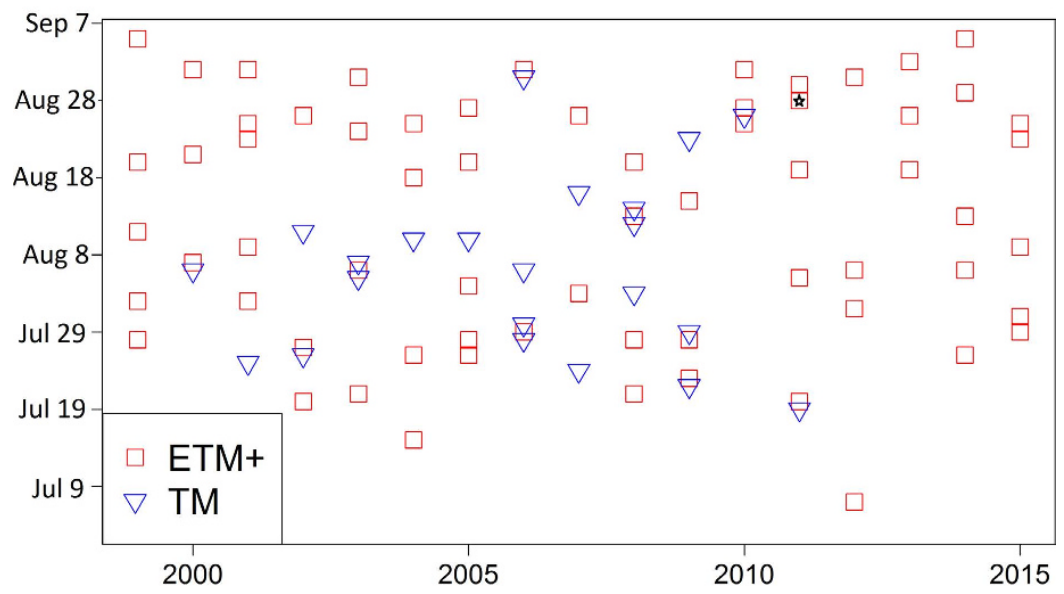

Figure 3. Distribution of Landsat images used to characterize the postfire vegetation recovery trajectory. The image (August 28, 2011) used for calculating vegetation indices and correlating with field data is marked with an asterisk.

where $\rho N I R$ is the reflectance in the NIR wavelength, Landsat TM/ETM + band $4(0.76-0.90 \mu \mathrm{m})$ and $\rho S W I R 2$ is the reflectance in the SWIR wavelength, Landsat TM/ETM+ band $7(2.08-2.35 \mu \mathrm{m})$.

A histogram approach and results from a previous publication ${ }^{45}$ were combined to determine the dNBR threshold $(>0.1)$ to separate burned pixels from unburned pixels. A total of 84 fires, ranging from 8 to 239,500 ha with a median of 468 ha, that burned over 685,930 ha during this period, were delineated based on this approach.

Field measurement of postfire stand density and aboveground NPP. To determine the vegetation index that serves as the best proxy for recovery, correlations were computed between field measurements and remotely-sensed vegetation indices. Postfire tree recruitment and aboveground net primary productivity (ANPP) at 83 plots were collected in August 2011 from an 8700 ha fire scar burned in June 2000. These plots were stratified by fire severity classes (e.g., low, medium, and high) and aspect (e.g., south-slope, north-slope, and flat). At each plot, a $50 \mathrm{~m} \times 50 \mathrm{~m}$ area was selected that was relatively homogenous in vegetation recovery, terrain and burn severity. Three $5 \mathrm{~m} \times 5 \mathrm{~m}$ subplots were randomly selected within this area. Species, basal diameter, and height for all tree recruits were recorded within each subplot. The seedling density within the plot was calculated as the average of three subplots. ANPP was calculated using allometric models developed for young saplings of each species ${ }^{19,20}$.

Variable calculation. Vegetation indices. Wildfires cause a drastic reduction in the reflectance of visible-to-NIR wavelengths $(\sim 0.4-\sim 0.9 \mu \mathrm{m})$ due to the loss of photosynthetic vegetation, and an accompanied increase in the reflectance of SWIR wavelengths $(\sim 1.5-\sim 2.3 \mu \mathrm{m})$ due to increased char/ash ${ }^{43,46}$. Postfire vegetation recovery has the opposite effect on spectral reflectance. To capture the postfire vegetation regrowth processes, four vegetation indices were selected: the Normalized Difference Vegetation Index (NDVI), the Normalized Difference Water Index (NDWI), Tasseled Cap Wetness (TCW), and Tasseled Cap Angle (TCA).

NDVI is a widely used index to quantify the amount of photosynthetically active vegetation or greenness, green vegetation fraction, leaf area index, and net primary production on the ground. As such, the index is also widely used as a proxy for postfire recovery in various ecosystems ${ }^{25,47}$. The index is calculated:

$$
N D V I=\frac{\rho N I R-\rho R e d}{\rho N I R+\rho R e d}
$$

where $\rho$ Red is the reflectance in the red wavelength, Landsat TM/ETM + band $3(0.63-0.69 \mu \mathrm{m})$

NDWI has been shown to be less sensitive to atmospheric scattering and more sensitive to water absorption and canopy structure ${ }^{26,48}$, making it potentially suitable to detect structural changes associated with vegetation recovery. NDWI is calculated

$$
N D W I=\frac{\rho N I R-\rho S W I R 1}{\rho N I R+\rho S W I R 1}
$$

where $\rho S W I R 1$ is the reflectance in the SWIR wavelength, Landsat TM/ETM+ band $5(1.55-1.75 \mu \mathrm{m})$

Tasseled Cap (TC) indices are well-known linear transformations of band reflectance and have been widely used for forest mapping and change detection. TC Wetness (TCW) is usually interpreted in vegetated areas as an index of canopy structure, soil or surface moisture, or possibly an estimate of the amount of dead or dried vegetation $^{49}$. Recent analysis has found that TCW is positively associated with woody vegetation cover in the Amazon ${ }^{50}$. Standard TCW transformation coefficients for Landsat bands were derived from the literature ${ }^{51}$. 
TCA is defined as the angle formed by TC greenness (TCG) and TC brightness (TCB) in the vegetation plane (Equation 4), representing the proportion of vegetated area to non-vegetated area. TCA has been used to characterize vegetation density and succession in coniferous forests ${ }^{27,52}$, and has shown good correlation with LiDAR-derived canopy structure (i.e., canopy cover and height) in a temperate forest in British Columbia, Canada $^{53}$. Denser forest stands show higher TCA values.

$$
T C A=\arctan (T C G / T C B)
$$

Fire severity. Relative dNBR (RdNBR) images for each fire patch were calculated and used as a proxy for fire severity ${ }^{43,44}$. RdNBR is calculated by dividing dNBR by the square-root of the prefire NBR. Positive RdNBR values represent a decrease in vegetation cover, just like $\mathrm{dNBR}$, while negative values represent an increase in vegetation cover. RdNBR removes the biasing effect of the prefire conditions on NBR, and makes fire severity comparable among different fires and vegetation types ${ }^{44}$.

Spatial variability of fire severity (RdNBR_Var) and Shape index (SHP_IDX) influence seed availability and delivery because they are representative of residual surviving trees and adjacent unburned forest ${ }^{11}$. The RdNBR_ Var was calculated as the standard deviation of RdNBR within a $120 \mathrm{~m}$ circle based on the seed dispersal ability of Larch $^{54}$. The SHP_IDX measures the shape complexity and becomes larger as patch shape becomes more irregular. Shape index was calculated as patch perimeter divided by the minimum perimeter possible for a maximally compact patch of the corresponding patch area ${ }^{55}$. Distance to nearest unburned forest (D2B) was included to approximate the effect of fire on seed delivery. Fire year (Year +0$)$ NDVI was incorporated into the model and used as a proxy for postfire vegetation condition (i.e., remaining vegetation and availability of open space for regeneration).

Climate variability. Monthly temperature and precipitation at 0.5 degree resolution from 1986 to 2015 was downloaded from the Climate Research Unit at the University of East Anglia (https://crudata.uea.ac.uk/cru/data/ $\mathrm{hrg} /)^{56}$. Climate anomalies were used based on the rationale that climate anomalies remove the underlying spatial variability in long-term climate data and emphasize temporal deviations and are therefore effective indicators of regional droughts and other meteorological fluctuations. Monthly climate anomalies were calculated as the difference between monthly climate measurements and long-term (1986-2015) monthly climate measurement averages. The immediate and long-term climate anomalies were summarized to account for the potential effect of climate variability on vegetation recovery at different temporal scales.

Immediate postfire climate conditions influence plant regeneration and establishment via soil moisture conditions and site quality. Immediate postfire climate anomalies were summarized for summer (June, July, August) and winter (December, January, February) at fire years $($ Year +0$)$ and one year after fire $($ Year +1$)$. Long-term climate conditions influence plant survival and growth rates. Long-term postfire climate anomalies were summarized as the average summer climate anomaly from Year +0 to Year +4 when explaining the variation in Year +5 vegetation recovery. Note that one climate pixel encompassed many 30-meter Landsat pixels, providing a single climate variable value across those 30 -meter pixels.

Topography. A 30-meter resolution Digital Elevation Model (DEM) for the study area was acquired from the SRTM (Shuttle Radar Topography Mission) website (http://www2.jpl.nasa.gov/srtm/). In this analysis, elevation (m), slope (degree), and potential solar radiation (Poten_rad) were used. The Poten_rad was used to estimate the potential influence of solar radiation on soil moisture ${ }^{57}$, and is calculated as follows:

$$
\text { Poten_rad }=\cos ((\theta-225) /(180 * 3.14159))
$$

where $\theta$ is the aspect derived from the Arc/Info "aspect" function. Poten_rad ranged from -1 to 1, with higher values indicating higher potential solar radiation.

Analysis. Exploring vegetation indices as proxies for recovery. To understand which vegetation indices were better indicators of postfire forest recovery, field measurements of seedling density and ANPP were compared with NDVI, NDWI, TCW, and TCA. To minimize the potential spatial mismatch of footprints of field observations and Landsat pixels, values of vegetation indices were averaged within 3 by 3 pixel windows covering the field measurements. Pearson correlations among log-transformed seedling densities, ANPP, and vegetation indices from ETM+ image acquired on August 28, 2011 were calculated. The correlations were done using the 'pairs. panels' function in the 'psych' package in $\mathrm{R}^{58}$.

Postfire vegetation recovery trajectory. To explore postfire spectral trajectories, time series of vegetation indices were sampled before and after fires. According to the results of a global Moran's I test on NDWI, the minimum distance between spatial samples required to remove spatial autocorrelation should be at least 1000 meters. The values of vegetation indices at each sampling point were averaged within a 3 by 3 pixel window to remove the potential geolocation bias among images. To focus exclusively on forested cells, only cells with tree cover greater than $30 \%$ in 2000 were sampled based on the Landsat-derived Global Forest Change dataset ${ }^{59}$. Then, the mean values of vegetation indices were plotted against time since fire to show the postfire spectral trajectory.

Influence of climate variability, fire, and topography on postfire recovery. The spatial locations used to sample time series vegetation indices were also used to sample the values of climate variability, fire characteristics, and topography (predictors). Boosted regression trees (BRT) were used to model vegetation recovery as a function of predictors (Table 1). BRT models are a stochastic extension of classification and regression trees which are 
"boosted" with additional trees that best reduce the loss function at each step ${ }^{60}$. The BRT method combines the advantages of regression trees, which relate a response to their predictors by recursive binary splits, and boosting algorithms, which combine many simple models to give improved predictive performance. The relative importance and partial dependence of each predictor is calculated in the BRT, along with the interactions between the predictors. The BRT analysis was run in R using the 'dismo' package ${ }^{61}$.

The BRT ensemble process is controlled by learning rate $(l r$, the rate at which the model is built), tree complexity ( $t c$, the level of variable interactions), and the number of trees ( $n t)$ to balance model fit and predictive performance. A bag fraction was also used to split the data into the proportion of the data set used to train versus cross-validate the models. In this analysis, predictive deviance, representing the goodness of fit between predicted and observed values, was used to select the best combination of parameters ( $l r, t c$ and $n t)$ using a 10 -fold cross validation $^{61}$.

Predictors that had a relative importance greater than 5\% were reported, along with their marginal effects on postfire recovery. The BRT model determines the variable importance based on the idea that the relevance of each predictor in a classification tree can be measured as the number of times it is selected for splitting the tree. The relative importance of each predictor was evaluated as the average number of times that the predictor was used in splitting the boosted regression trees, weighted by the squared improvement to the model, averaged over all trees ${ }^{61}$. Partial dependence functions estimate the impact of a given predictor on the dependent variable by statistically controlling for the average effect of all other predictors. The two-way interactive effect of variables was quantified as the variance caused by the two predictors while controlling for the average effect of all other predictors. The joint partial dependence plots were used to provide a clear and easily interpretable depiction of complex interactions ${ }^{61}$.

\section{Results}

Correlations among field measurements of postfire stand density, ANPP, and vegetation indices. As expected, vegetation indices were highly correlated with each other, but the strength of the correlation decreased as the vegetation indices used different proportions of each wavelength (Fig. 4). All vegetation indices had a stronger relationship with tree density than with ANPP, suggesting a decoupling between ecosystem structure and function, and remotely sensed vegetation indices. The NDWI had the strongest relationship $\left(R^{2}=0.66\right)$ with tree density, while the TCW had the weakest relationship $\left(R^{2}=0.51\right)$. The widely-used NDVI ranked third in terms of correlation with tree density $\left(R^{2}=0.60\right)$. Density plot indicated that these field measurements are representative of fire severity and postfire vegetation indices across the study area, despite they are mainly from high elevations (Supplementary Fig. S1). As such, NDWI is the most robust proxy for postfire vegetation recovery in boreal Larch forests of Northeastern China.

Postfire vegetation recovery trajectory. After controlling for spatial autocorrelation and excluding non-forest pixels, a total of 13,112 pixels were sampled to examine postfire vegetation recovery trajectories. The four selected vegetation indices dropped dramatically after fire disturbance, and such drops were larger for NDWI and TCA (Fig. 5). All vegetation indices, except for TCW, increased monotonically until 5-6 years after fires, but become more variable thereafter. TCW did not show a clear trend after fires. Five years after fire, the NDVI, NDWI, and TCW were not statistically significantly different from pre-fire levels. Such a rate of spectral recovery is comparable to that from Larix sibirica in northern Mogolia and mixed-conifer forests of the Sierra Nevada, California, USA ${ }^{47,62}$, but much faster than that from Larch forests in Central Siberia, Russia ${ }^{25}$. As a result, vegetation indices 5 years following fire (Year $+5 \mathrm{VI}$ ) were chosen as a proxy for short-term vegetation recovery.

Influences of climate, fire, and topography on postfire vegetation recovery. Based on the previous analysis, NDWI at 5 years after fire represents a robust proxy for short-term vegetation recovery due to its strong correlation with field measurements of stand density (Figs 4 and 5). The best BRT model, with a sample size of 13,112 , explained $64.8 \%$ of variance with $t c=3, n t=900, l r=0.1$, and a bag fraction of 0.5 . There was no strong multi-collinearity among predictors. The BRT analysis showed that fire characteristics, climate variability, and environmental filters all had significant influences on short-term vegetation recovery (Fig. 6). Fire severity had the strongest influence on postfire recovery, followed by elevation, shape index, spatial variability of fire severity, distance to unburned forest, and summer precipitation one year after fire. Partial dependencies from the fitted model indicate that, when other variables were held constant, vegetation recovery was negatively correlated with fire severity, spatial variability of fire severity, elevation, and distance to unburned forest, and positively correlated with shape complexity and summer precipitation one year after fire (Fig. 7). Forcing the marginal effects in the model to be monotonic had little effect on the overall shape of the estimated effects of predictors on vegetation recovery. The strongest interaction was found among fire severity, spatial variability of fire severity, elevation, and distance to unburned patches. Vegetation recovery was faster in sites where fire severity and its spatial variability was lower, closer to unburned patches, and at lower elevations (Fig. 8).

\section{Discussion}

Remote sensing of postfire vegetation recovery. The results show that ecosystem structure is more strongly correlated with SWIR-based vegetation indices (e.g., NDWI) than with Red/NIR-based vegetation indices (NDVI), suggesting that SWIR-based vegetation indices are better indicators for postfire vegetation recovery in boreal Larch forests. Previous analyses also showed that SWIR-based vegetation indices are sensitive to the interaction between water content and canopy structure in boreal ${ }^{27}$, temperate ${ }^{48}$, and tropical forests ${ }^{26,63}$. This is because the spectral reflectances at SWIR wavelengths are sensitive to canopy water content and vegetation structure, and also have large dynamic changes ${ }^{64}$. The Red/NIR-based vegetation indices are mainly related to "greenness", which 


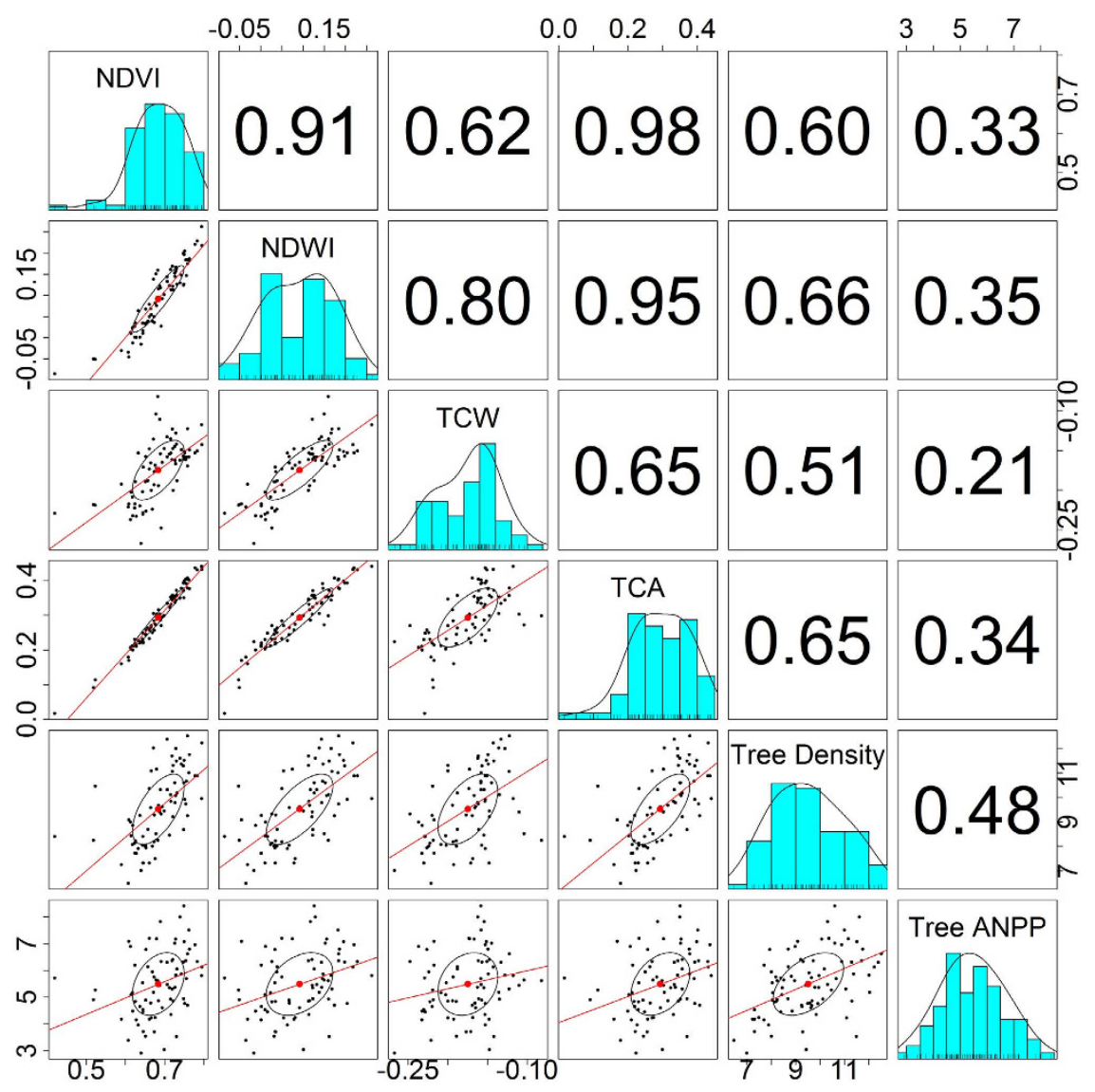

Figure 4. Correlation among field measurement of stand density and ANPP, and different vegetation indices. Circle represents correlation ellipses among variables. NDVI: Normalized Difference Vegetation Index, NDWI: Normalized difference water index, TCW: Tasseled Cap wetness, TCA: TC Angle.

reflects the horizontal surface area of photosynthesizing vegetation. Therefore, SWIR-based vegetation indices are sensitive to vegetation structure and dynamics ${ }^{25,65}$, and provide good indicator of forest recovery.

Spatial controls of postfire vegetation recovery. Fire severity and its spatial variability played a dominant role in determining potential vegetation recovery following fire in this Siberian boreal larch forest. Environmental filters appear to be a weaker force, but interacted strongly with fire severity to influence postfire recovery. Immediate postfire climate conditions play a minor, but significant role in vegetation recovery. This analysis thus revealed that postfire recovery in boreal Larch forests of Northeastern China was collectively controlled by processes that controlled seed availability, site condition, and climate variability after fire. Anticipated increases in fire severity and moisture stress ${ }^{66}$, interacting with gradients of environmental conditions, will have significant influences on vegetation structure and function, and forest feedbacks to climate ${ }^{67,68}$.

Previous research has demonstrated that fire determines vegetation recovery through its influence on seed availability and site conditions, and species' life-history traits. For example, in fire "embracer"-dominated forests, consumption of organic soil layers favors deciduous hardwood regeneration over coniferous regeneration and thus alters successional trajectories after fire9. In fire "avoider"-dominated forests, deciduous hardwoods are generally less dispersal-limited (due to their relatively long dispersal distances) than evergreen conifers (shorter dispersal distances). Thus, the landscape-scale balance between deciduous hardwoods and evergreen conifers in terms of seed limitation is the primary mechanism for successional trajectory changes after fire ${ }^{13}$. In a 'resister'-dominated (e.g., larch) forests, postfire recovery is generally not considered seed-limited because it frequently survives fire due to its species' thick bark, which has a low thermal diffusivity. Contrary to the expectation, this analysis suggested that seed availability is likely the primary mechanism to limit postfire forest recovery in the larch forests of Northeastern China, because the thin organic soil layer $(<10 \mathrm{~cm})$ is usually completely consumed by fires ${ }^{19,20}$.

The seed limitation on postfire recovery was reaffirmed by the fact that the spatial variability of fire severity also had significant negative effects on vegetation recovery, potentially due to its effect on vegetation legacies and seed availability. Indeed, vegetation legacies after fire affect seed availability and play a pivotal role in shaping patterns of community assembly after fire in these low-diversity boreal forests ${ }^{12,13}$. As Larch forests are becoming increasingly seed-limited in response to intensifying fire regimes, lack of seed may potentially change forests to alternative vegetation-disturbance feedbacks under a future warmer and drier climate (e.g., shrubland or grassland with frequent, high-severity, fires), consistent with conclusions from a field-based study ${ }^{20}$. 


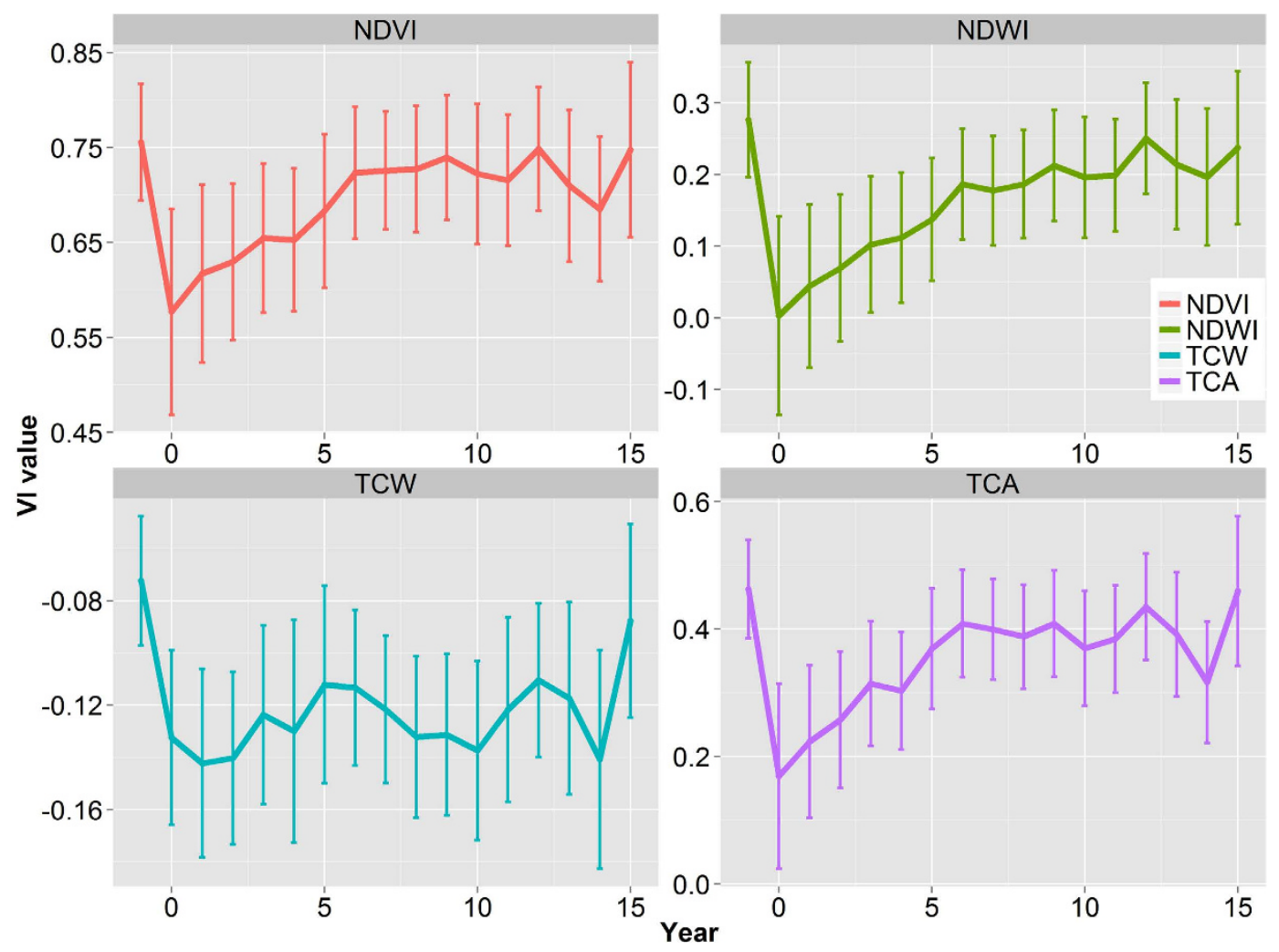

Figure 5. Postfire trajectories of vegetation indices in the study area. Error bar stands for plus-or-minus standard deviation. NDVI: Normalized Difference Vegetation Index, NDWI: Normalized difference water index, TCW: Tasseled Cap wetness, TCA: TC Angle.

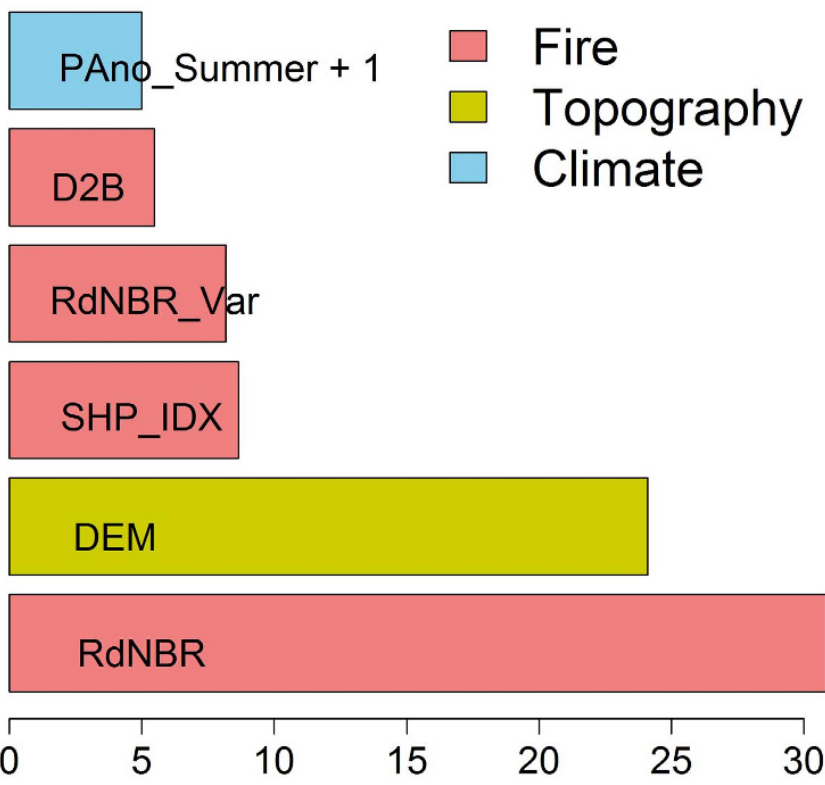

Figure 6. Relative influences of variables that explained greater than $5 \%$ of the variation from boosted regression tree models of vegetation recovery. For explanation of variables and their units see Table 1.

Climate conditions in the first postfire growing season play an important role for vegetation recovery, consistent with a recent analysis in the Sierra Nevada ${ }^{47}$. Specifically, higher growing season precipitation one year after fire has a positive influence on postfire recovery, while temperature and longer-term climate conditions have no significant effects. This suggests that recovery of plant demography (i.e., colonization and establishment) is 

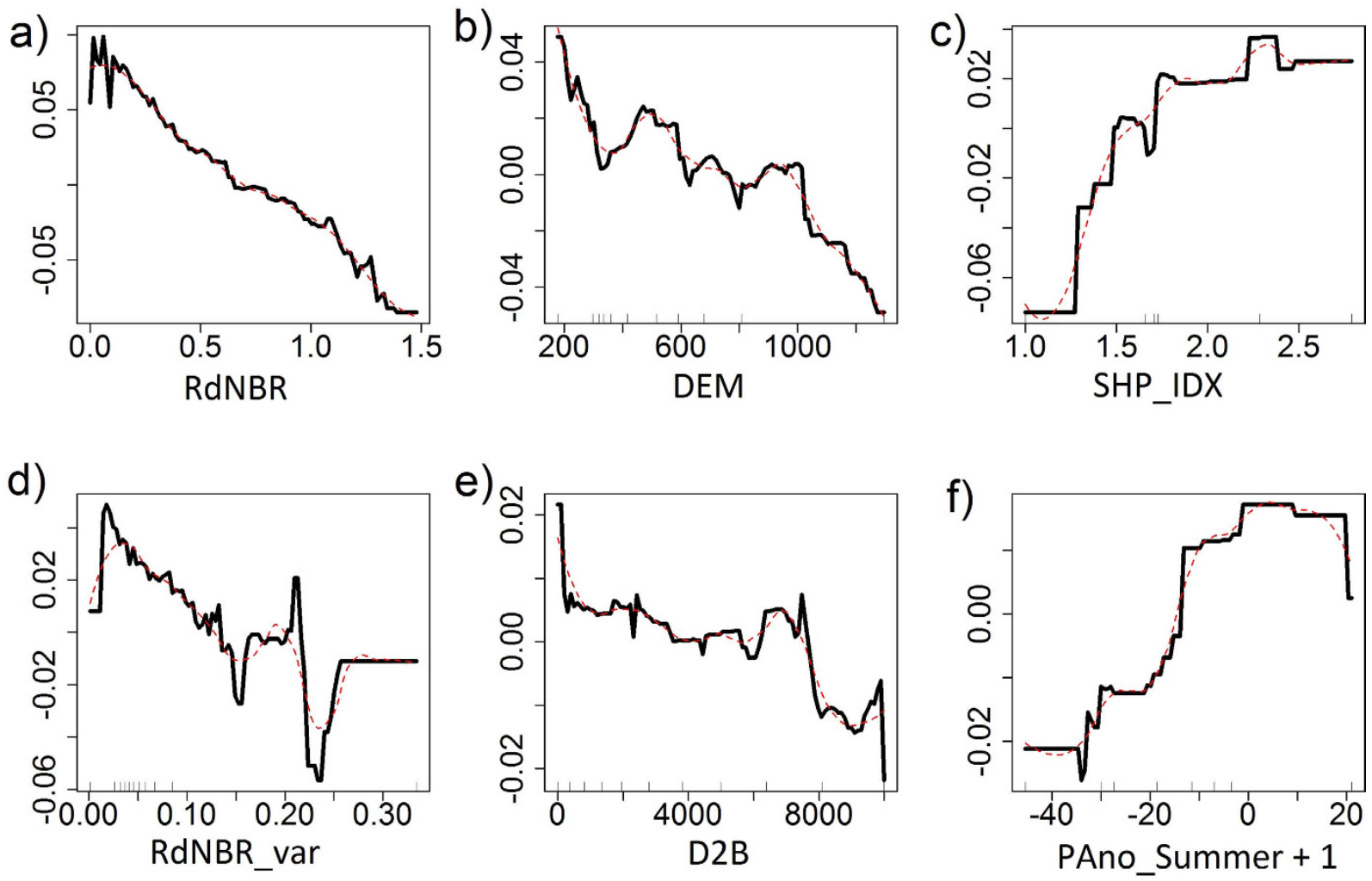

Figure 7. Partial dependency plots for variables in a boosted regression tree predicting postfire vegetation recovery. Partial dependency plots represent the estimated marginal effect of a variable on postfire recovery when all other variables are held at their average. The $y$-axis indicates the relative effects of a variable ( $\mathrm{x}$-axis) on vegetation recovery. Red lines indicate the marginal effects constrained in the model to be monotonic. Tick marks at the $\mathrm{x}$-axis indicate the deciles ( $10 \%$ quantiles) of the observed distribution of continuous predictor variables. For explanation of variables and their units see Table 1.

strongly controlled by moisture availability. The effect of moisture availability on initial postfire colonization and establishment is more critical than longer-term forest growth on vegetation recovery. Similar results have been found in many other ecosystems $s^{17,47,69}$. As the frequency and severity of drought is expected to increase under a warmer and drier climate, elevated chances of postfire water stress may have a significant influence on ecosystem composition and function ${ }^{20}$. Recent climate warming has resulted in a rather uniform trend toward higher plant productivity and forest cover gain in the North, and a trend toward decreased productivity and forest cover loss in southern Siberian boreal forests ${ }^{66}$, similar to observations from Canada's boreal forests ${ }^{70}$.

Understanding the interactive effects between fast-changing fire regimes and slow-changing climate on ecosystem change in Siberian larch forests is critical for anticipating its potential role in Earth system. Unlike the typical boreal fire regime in North America, the fire regime in Siberian Larch forests is characterized by early season (March-May), low-intensity surface fires, mixed with infrequent stand-replacing fires under extreme climate conditions $s^{5,71-73}$. If an intensified fire regime unfolded as expected under warmer and drier climate conditions, accelerated changes in species composition or even biome boundaries may potentially hasten transitions to 'no-analogue communities' in the region ${ }^{74}$. If large-scale changes in biotic communities occur after disturbance, there will also be significant consequences for many ecosystem processes, such as carbon cycling and thawing of the permafrost ${ }^{66}$. Therefore, the potential interactions among climate, fire, and ecosystem change in Siberian Larch forests warrant further research.

Uncertainties. The climate data used had a much coarser resolution compared to topography and fire data. This may have resulted in a decreased explanation of spatial variation and an underestimation of the influence of climate on vegetation recovery. To assess such an effect, a BRT analysis was conducted at the fire patch level $(\mathrm{n}=84)$, with $t c=3, n t=240, l r=0.01$, and bag fraction $=0.75$. This model explained $84.8 \%$ of the variation in vegetation recovery, and confirmed that fire severity had the strongest influence on the variable, followed by elevation, and both had negative correlations with vegetation recovery (Supplementary Fig. S2). Postfire climate variability explained less than $5 \%$ of the variation. Because topography and associated soil moisture may influence vegetation recovery, three additional BRT models were fit, stratified by potential solar radiation. All three models suggested that the major conclusions of the original analysis were robust across different topographic positions and different scales (Supplementary Fig. S3). This showed that the scale mismatch between climate and environmental variables did not change the main findings of this analysis, possibly due to the following two reasons. First, Moran's $I$ was 

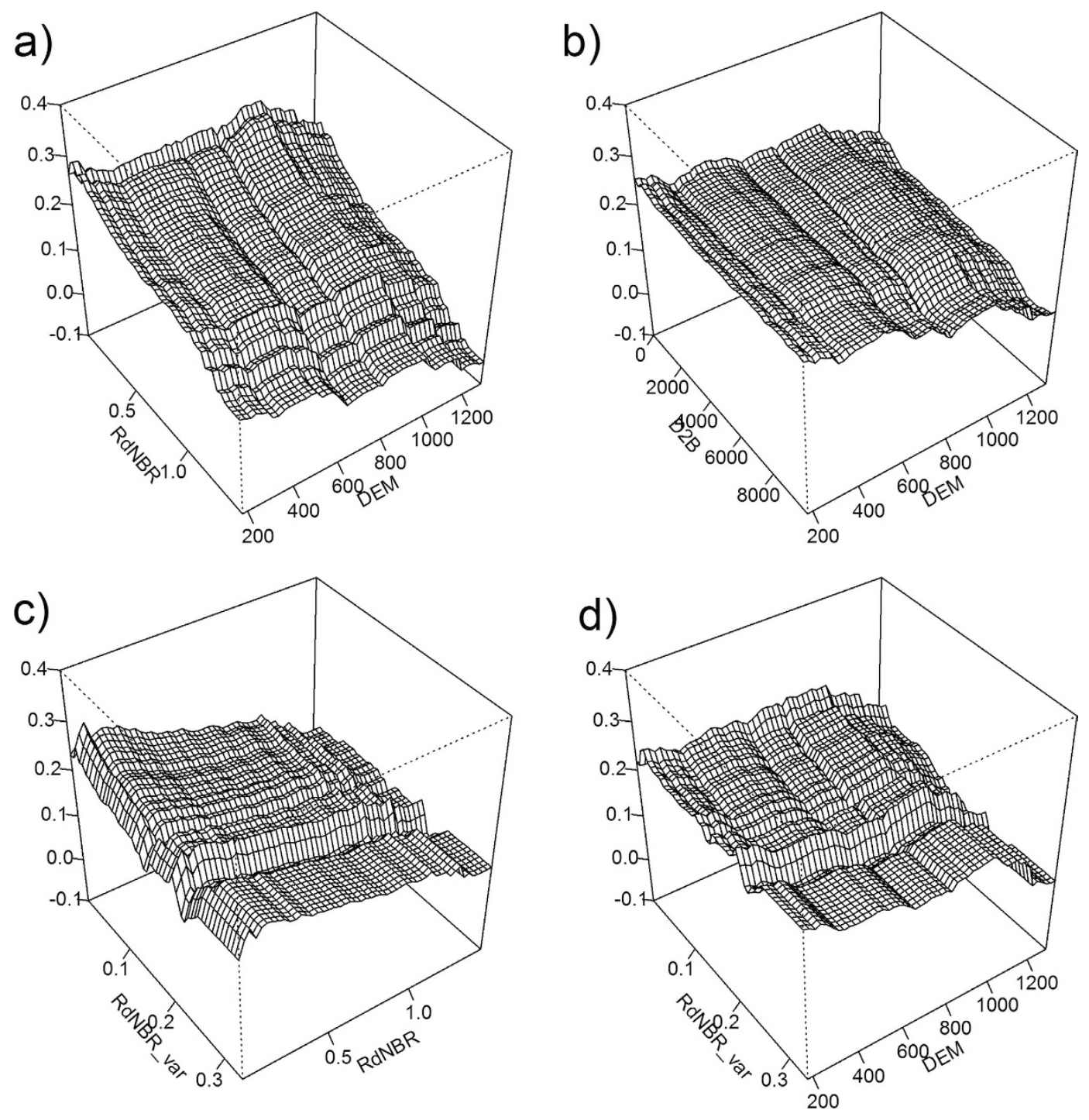

Figure 8. Three-dimensional partial dependence plots for the top four strongest interactions in the model for postfire vegetation recovery. All variables except those graphed are held at their means. The $\mathrm{z}$-axis indicates the relative effects of interactions between variables ( $\mathrm{x}$ - and $\mathrm{y}$-axis) on vegetation recovery. For explanation of variables and their units see Table 1.

used to exclude the spatial structures of variables. Second, climatic anomalies were used to remove the underlying spatial variability in long-term climate and emphasize temporal fluctuation in climatic condition at local scales.

Although time series analyses of remotely sensed data provides a method to monitor forest recovery and vegetation reestablishment following disturbances ${ }^{75-77}$, the linkage between spectral recovery and ecological or silvicultural understanding of forest recovery has rarely been made ${ }^{78}$. From an ecological perspective, forest recovery is typically considered as the reestablishment of forest biomass or canopy structure following disturbance and may be indicated by vegetation structural properties, photosynthetic capacity, height, biomass, and heterogeneity $^{79}$. Therefore, the vegetation recovery in this analysis should be interpreted as spectral recovery, rather than structural or functional recovery from an ecological perspective. In the future, multi-sensor approaches combining airborne LIDAR with satellite data may link sensor data to actual forest structure and biomass data at fine resolution over large spatial scales.

Vegetation recovery is a multi-faceted process. Nevertheless, most studies have primarily focused on investigating recovery of photosynthetically active vegetation or "greenness" by remote sensing approaches. However, spectral recovery does not necessarily reflect recovery in other ecosystem variables such as biogeochemistry, radiation budgets, or water balance. Multiple recovery indicators should be used as a way to provide complementary measurements of vegetation dynamics, and help trend interpretation and attribution of proximate causes.

\section{Conclusions}

Two key mechanisms governing postfire recovery in boreal forests are seed availability related to fire characteristics and seedling establishment/survival related to site and postfire climatic conditions ${ }^{16}$. Testing the interactive 
effects of climatic conditions and fire characteristics in controlling postfire recovery across multiple burned patches provides an indicator of forest resilience to future climate and disturbance in boreal forests. This analysis revealed that postfire recovery in boreal Larch forests of Northeastern China was primarily controlled by seed availability in relation to fire severity and its spatial variability. Once seeds arrive, successful germination and seedling establishment are governed by moisture conditions and local site factors. This study suggested that forest resilience in the Siberian Larch region was collectively controlled by processes that controlled seed availability, as well as by site conditions and climate variability. If future drought and fire regimes manifest as expected in this region, the seed limitation and climate-induced regeneration failure will become more prevalent and severe, which may cause widespread forest dieback and compositional change. More research is needed to address the degree to which climate change-induced intensification of fire regimes will cause forests to shift to alternative stable states, as well as how changes in fire regimes may impact regional biogeochemistry, energy, and water cycles.

\section{References}

1. Gauthier, S. et al. Boreal forest health and global change. Science 349, 819-822, doi: 10.1126/science.aaa9092 (2015).

2. Bonan, G. B. Forests and climate change: forcings, feedbacks, and the climate benefits of forests. Science 320, 1444-1449 (2008).

3. Steffen, W. et al. Planetary boundaries: Guiding human development on a changing planet. Science 347, 1259855 (2015).

4. Young, A. M., Higuera, P. E., Duffy, P. A. \& Hu, F. S. Climatic thresholds shape northern high-latitude fire regimes and imply vulnerability to future climate change. Ecography, 39, 1-12, doi: 10.1111/ecog.02205 (2016).

5. Liu, Z. et al. Spatial patterns and drivers of fire occurrence and its future trend under climate change in a boreal forest of Northeast China. Global Change Biology 18, 2041-2056, doi: 10.1111/j.1365-2486.2012.02649.x (2012).

6. de Groot, W. J., Flannigan, M. D. \& Cantin, A. S. Climate change impacts on future boreal fire regimes. For. Ecol. Manage. 294, 35-44, doi: http://dx.doi.org/10.1016/j.foreco.2012.09.027 (2013).

7. Bond-Lamberty, B., Peckham, S., Ahl, D. \& Gower, S. Fire as the dominant driver of central Canadian boreal forest carbon balance. Nature 450, 89-92 (2007)

8. Garcia, R. A., Cabeza, M., Rahbek, C. \& Araújo, M. B. Multiple dimensions of climate change and their implications for biodiversity. Science 344, 486-497, doi: 10.1126/science.1247579 (2014).

9. Johnstone, J. F., Hollingsworth, T. N., Chapin III, F. S. \& Mack, M. C. Changes in fire regime break the legacy lock on successional trajectories in Alaskan boreal forest. Global Change Biol. 16, 1281-1295 (2010).

10. Scheffer, M. et al. Thresholds for boreal biome transitions. PNAS 109, 21384-21389, doi: 10.1073/pnas.1219844110 (2012).

11. Turner, M. G. Disturbance and landscape dynamics in a changing world. Ecology 91, 2833-2849 (2010).

12. Brown, C. D., Liu, J., Yan, G. \& Johnstone, J. F. Disentangling legacy effects from environmental filters of postfire assembly of boreal tree assemblages. Ecology 96, 3023-3032, doi: 10.1890/14-2302.1 (2015).

13. Tautenhahn, S. et al. Dispersal limitation drives successional pathways in Central Siberian forests under current and intensified fire regimes. Glob Chang Biol 22, 2178-2197, doi: 10.1111/gcb.13181 (2016).

14. Turner, M. G., Romme, W. H., Gardner, R. H. \& Hargrove, W. W. Effects of fire size and pattern on early succession in Yellowstone National Park. Ecol. Monogr. 67, 411-433 (1997).

15. Buma, B. et al. The Impacts of Changing Disturbance Regimes on Serotinous Plant Populations and Communities. Bioscience 63, 866-876, doi: 10.1525/bio.2013.63.11.5 (2013).

16. Harvey, B. J., Donato, D. C. \& Turner, M. G. High and dry: post-fire tree seedling establishment in subalpine forests decreases with post-fire drought and large stand-replacing burn patches. Global Ecol. Biogeogr. 25, 655-669, doi: 10.1111/geb.12443 (2016).

17. Petrie, M. D. et al. A review of precipitation and temperature control on seedling emergence and establishment for ponderosa and lodgepole pine forest regeneration. For. Ecol. Manage. 361, 328-338, doi: http://dx.doi.org/10.1016/j.foreco.2015.11.028 (2016).

18. Brown, P. M. \& Wu, R. Climate and disturbance forcing of episodic tree recruitment in a southwestern ponderosa pine landscape. Ecology 86, 3030-3038, doi: 10.1890/05-0034 (2005).

19. Cai, W. et al. Post-fire tree recruitment of a boreal larch forest in Northeast China. For. Ecol. Manage. 307, 20-29 (2013).

20. Liu, Z. \& Yang, J. Quantifying ecological drivers of ecosystem productivity of the early-successional boreal Larix gmelinii forest. Ecosphere 5, art84, doi: 10.1890/es13-00372.1 (2014)

21. Harvey, B. J. \& Holzman, B. A. Divergent successional pathways of stand development following fire in a California closed-cone pine forest. Journal of Vegetation Science 25, 88-99 (2014).

22. Kashian, D. M. et al. Postfire changes in forest carbon storage over a 300-year chronosequence of Pinus contorta-dominated forests. Ecol. Monogr. 83, 49-66 (2013).

23. Turner, M. G., Whitby, T. G., Tinker, D. B. \& Romme, W. H. Twenty-four years after the Yellowstone Fires: Are postfire lodgepole pine stands converging in structure and function? Ecology, 97, 1260-1273, doi: 10.1890/15-1585.1 (2016).

24. Chu, T. A. \& Guo, X. L. Remote Sensing Techniques in Monitoring Post-Fire Effects and Patterns of Forest Recovery in Boreal Forest Regions: A Review. Remote Sensing 6, 470-520, doi: 10.3390/rs6010470 (2014).

25. Cuevas-gonzalez, M., Gerard, F., Balzter, H. \& Riano, D. Analysing forest recovery after wildfire disturbance in boreal Siberia using remotely sensed vegetation indices. Global Change Biol. 15, 561-577 (2009).

26. Anderson, L. O. et al. Remote sensing detection of droughts in Amazonian forest canopies. New Phytol. 187, 733-750, doi: 10.1111/j.1469-8137.2010.03355.x (2010).

27. Gómez, C., White, J. C. \& Wulder, M. A. Characterizing the state and processes of change in a dynamic forest environment using hierarchical spatio-temporal segmentation. Remote Sens. Environ. 115, 1665-1679, doi: http://dx.doi.org/10.1016/j.rse.2011.02.025 (2011).

28. Berner, L. et al. Cajander larch (Larix cajanderi) biomass distribution, fire regime and post-fire recovery in northeastern Siberia. Biogeosci. Disc. 9, 7555-7600 (2012).

29. Gitas, I., Polychronaki, A., Mitri, G. \& Veraverbeke, S. Advances in Remote Sensing of Post-Fire Vegetation Recovery Monitoring-A review. (INTECH Open Access Publisher, 2012).

30. Osawa, A. et al. Permafrost Ecosystems: Siberian Larch Forests. Vol. 209502 (Springer, 2010).

31. Wu, J. et al. Vegetation and Climate Change during the Last Deglaciation in the Great Khingan Mountain, Northeastern China. PloS one 11, e0146261 (2016).

32. Xu, C. H., Li, Z. D. \& Qiu. Y. Fire disturbance history in virgin forest in northern region of daxinganling mountains. Acta Ecologica Sinica 17, 3-9 (1997).

33. Chang, Y. et al. Historic and current fire regimes in the Great Xing'an Mountains, northeastern China: Implications for long-term forest management. Forest Ecology and Management 254, 445-453, doi: 10.1016/j.foreco.2007.04.050 (2008).

34. Liu, Z., He, H. S. \& Yang, J. Emulating natural fire effects using harvesting in an eastern boreal forest landscape of northeast China. Journal of Vegetation Science 23, 782-795, doi: 10.1111/j.1654-1103.2012.01397.x (2012).

35. Wu, Z. W. et al. Development of Customized Fire Behavior Fuel Models for Boreal Forests of Northeastern China. Environmental Management, 48, 1148-1157 (2011). 
36. Johnstone, J. F. et al. Changing disturbance regimes, ecological memory, and forest resilience. Front. Ecol. Environ. 14, 369-378, doi: 10.1002/fee.1311 (2016).

37. Enright, N. J. et al. Interval squeeze: altered fire regimes and demographic responses interact to threaten woody species persistence as climate changes. Front. Ecol. Environ. 13, 265-272, doi: 10.1890/140231 (2015).

38. Nathan, R. \& Muller-Landau, H. C. Spatial patterns of seed dispersal, their determinants and consequences for recruitment. Trends Ecol. Evol. 15, 278-285 (2000).

39. Sulla-Menashe, D., Friedl, M. A. \& Woodcock, C. E. Sources of bias and variability in long-term Landsat time series over Canadian boreal forests. Remote Sens. Environ. 177, 206-219, doi: http://dx.doi.org/10.1016/j.rse.2016.02.041 (2016)

40. Masek, J. G. et al. A Landsat surface reflectance dataset for North America, 1990-2000. Geoscience and Remote Sensing Letters, IEEE 3, 68-72 (2006).

41. Zhu, Z. \& Woodcock, C. E. Object-based cloud and cloud shadow detection in Landsat imagery. Remote Sens. Environ. 118, 83-94, doi: http://dx.doi.org/10.1016/j.rse.2011.10.028 (2012).

42. Roy, D. P. et al. A general method to normalize Landsat reflectance data to nadir BRDF adjusted reflectance. Remote Sens. Environ. 176, 255-271, doi: http://dx.doi.org/10.1016/j.rse.2016.01.023 (2016).

43. Miller, J. D. \& Thode, A. E. Quantifying burn severity in a heterogeneous landscape with a relative version of the delta Normalized Burn Ratio (dNBR). Remote Sens. Environ. 109, 66-80 (2007).

44. Miller, J. D. et al. Calibration and validation of the relative differenced Normalized Burn Ratio (RdNBR) to three measures of fire severity in the Sierra Nevada and Klamath Mountains, California, USA. Remote Sens. Environ. 113, 645-656 (2009).

45. Fang, L. \& Yang, J. Atmospheric effects on the performance and threshold extrapolation of multi-temporal Landsat derived dNBR for burn severity assessment. International Journal of Applied Earth Observation and Geoinformation 33, 10-20, doi: http://dx.doi. org/10.1016/j.jag.2014.04.017 (2014).

46. Lentile, L. B. et al. Remote sensing techniques to assess active fire characteristics and post-fire effects. Int. J. Wildland Fire 15, 319-345 (2006).

47. Meng, R. et al. Effects of fire severity and post-fire climate on short-term vegetation recovery of mixed-conifer and red fir forests in the Sierra Nevada Mountains of California. Remote Sens. Environ. 171, 311-325, doi: http://dx.doi.org/10.1016/j.rse.2015.10.024 (2015).

48. Jin, S. \& Sader, S. A. Comparison of time series tasseled cap wetness and the normalized difference moisture index in detecting forest disturbances. Remote Sens. Environ. 94, 364-372, doi: http://dx.doi.org/10.1016/j.rse.2004.10.012 (2005).

49. Cohen, W. B. \& Goward, S. N. Landsat's role in ecological applications of remote sensing. Bioscience 54, 535-545 (2004).

50. Rufin, P., Müller, H., Pflugmacher, D. \& Hostert, P. Land use intensity trajectories on Amazonian pastures derived from Landsat time series. International Journal of Applied Earth Observation and Geoinformation 41, 1-10, doi: http://dx.doi.org/10.1016/j. jag.2015.04.010 (2015).

51. Huang, C. et al. Derivation of a tasselled cap transformation based on Landsat 7 at-satellite reflectance. Int. J. Remote Sens. 23, 1741-1748 (2002).

52. Price, K. \& Jakubauskas, M. Spectral retrogression and insect damage in lodgepole pine successional forests. Int. J. Remote Sens. 19, $1627-1632$ (1998).

53. Ahmed, O. S., Franklin, S. E. \& Wulder, M. A. Interpretation of forest disturbance using a time series of Landsat imagery and canopy structure from airborne lidar. Canadian Journal of Remote Sensing 39, 521-542 (2014).

54. Xu, H. C. Forest in Great Xing' an Mountains of China. (Science Press, 1998).

55. McGarigal, K. \& Marks, B. J. Spatial pattern analysis program for quantifying landscape structure. Gen. Tech. Rep. PNW-GTR-351. US Department of Agriculture, Forest Service, Pacific Northwest Research Station (1995).

56. Harris, I., Jones, P. D., Osborn, T. J. \& Lister, D. H. Updated high-resolution grids of monthly climatic observations-the CRU TS3.10 Dataset. Int. J. Climatology 34, 623-642, doi: 10.1002/joc.3711 (2014).

57. Franklin, J., McCullough, P. \& Gray, C. Terrain variables used for predictive mapping of vegetation communities in southern California, In: Wilson, J. P., Gallant, J. C. (Eds.), Terrain Analysis: Principles and Applications. Wiley, New York (2000).

58. R_Core_Team. R: A language and environment for statistical computing. R Foundation for Statistical Computing, Vienna, Austria. URL http://www.R-project.org/ (2013).

59. Hansen, M. C. et al. High-Resolution Global Maps of 21 $1^{\text {st }}$-Century Forest Cover Change. Science 342, 850-853, doi: 10.1126/ science. 1244693 (2013).

60. De’Ath, G. Boosted trees for ecological modeling and prediction. Ecology 88, 243-251 (2007).

61. Elith, J., Leathwick, J. \& Hastie, T. A working guide to boosted regression trees. J. Anim. Ecol. 77, 802-813 (2008)

62. Chu, T., Guo, X. \& Takeda, K. Remote sensing approach to detect post-fire vegetation regrowth in Siberian boreal larch forest. Ecol. Indicators 62, 32-46, doi: http://dx.doi.org/10.1016/j.ecolind.2015.11.026 (2016).

63. Koltunov, A., Ustin, S. L., Asner, G. P. \& Fung, I. Selective logging changes forest phenology in the Brazilian Amazon: Evidence from MODIS image time series analysis. Remote Sens. Environ. 113, 2431-2440, doi: http://dx.doi.org/10.1016/j.rse.2009.07.005 (2009).

64. Ollinger, S. V. Sources of variability in canopy reflectance and the convergent properties of plants. New Phytol. 189, 375-394, doi: 10.1111/j.1469-8137.2010.03536.x (2011).

65. Gellrich, M., Baur, P., Koch, B. \& Zimmermann, N. E. Agricultural land abandonment and natural forest re-growth in the Swiss mountains: A spatially explicit economic analysis. Agriculture, Ecosystems \& Environment 118, 93-108 (2007).

66. Schaphoff, S. et al. Tamm Review: Observed and projected climate change impacts on Russia’s forests and its carbon balance. For. Ecol. Manage. 361, 432-444, doi: http://dx.doi.org/10.1016/j.foreco.2015.11.043 (2016).

67. Alexander, H. D. et al. Implications of increased deciduous cover on stand structure and aboveground carbon pools of Alaskan boreal forests. Ecosphere 3, art45, doi: 10.1890/es11-00364.1 (2012).

68. Beck, P. S. et al. The impacts and implications of an intensifying fire regime on Alaskan boreal forest composition and albedo. Global Change Biol. 17, 2853-2866 (2011).

69. Broncano, M. J. \& Retana, J. Topography and forest composition affecting the variability in fire severity and post-fire regeneration occurring after a large fire in the Mediterranean basin. Int. J. Wildland Fire 13, 209-216 (2004).

70. Price, D. T. et al. Anticipating the consequences of climate change for Canada's boreal forest ecosystems 1. Environ. Rev. 21, 322-365 (2013).

71. Wooster, M. J. \& Zhang, Y. H. Boreal forest fires burn less intensely in Russia than in North America. Geophys. Res. Lett. 31, doi: 10.1029/2004gl020805 (2004)

72. Rogers, B. M., Soja, A. J., Goulden, M. L. \& Randerson, J. T. Influence of tree species on continental differences in boreal fires and climate feedbacks. Nature Geosci 8, 228-234, doi: 10.1038/ngeo2352 (2015).

73. de Groot, W. J. et al. A comparison of Canadian and Russian boreal forest fire regimes. For. Ecol. Manage. 294, 23-34, doi: 10.1016/j. foreco.2012.07.033 (2013)

74. Williams, J. W. \& Jackson, S. T. Novel climates, no-analog communities, and ecological surprises. Front. Ecol. Environ. 5, 475-482, doi: 10.1890/070037 (2007)

75. Kennedy, R. E., Yang, Z. \& Cohen, W. B. Detecting trends in forest disturbance and recovery using yearly Landsat time series: 1. LandTrendr-Temporal segmentation algorithms. Remote Sens. Environ. 114, 2897-2910 (2010).

76. Huang, C. et al. An automated approach for reconstructing recent forest disturbance history using dense Landsat time series stacks. Remote Sens. Environ. 114, 183-198 (2010). 
77. DeVries, B. et al. Tracking disturbance-regrowth dynamics in tropical forests using structural change detection and Landsat time series. Remote Sens. Environ. 169, 320-334, doi: http://dx.doi.org/10.1016/j.rse.2015.08.020 (2015).

78. Bartels, S. F., Chen, H. Y. H., Wulder, M. A. \& White, J. C. Trends in post-disturbance recovery rates of Canada's forests following wildfire and harvest. For. Ecol. Manage. 361, 194-207, doi: http://dx.doi.org/10.1016/j.foreco.2015.11.015 (2016).

79. Frolking, S. et al. Forest disturbance and recovery: A general review in the context of spaceborne remote sensing of impacts on aboveground biomass and canopy structure. Journal of Geophysical Research-Biogeosciences 114, doi: 10.1029/2008jg000911 (2009).

\section{Acknowledgements}

This work was supported by the National Natural Science Foundation of China (31100345 and 31470517) and CAS Pioneer Hundred Talents Program. The author thanks L. Annie Cooper for language edits and feedback on earlier versions of this manuscript.

\section{Additional Information}

Supplementary information accompanies this paper at http://www.nature.com/srep

Competing financial interests: The author declares no competing financial interests.

How to cite this article: Liu, Z. Effects of climate and fire on short-term vegetation recovery in the boreal larch forests of Northeastern China. Sci. Rep. 6, 37572; doi: 10.1038/srep37572 (2016).

Publisher's note: Springer Nature remains neutral with regard to jurisdictional claims in published maps and institutional affiliations.

(c) (i) This work is licensed under a Creative Commons Attribution 4.0 International License. The images or other third party material in this article are included in the article's Creative Commons license, unless indicated otherwise in the credit line; if the material is not included under the Creative Commons license, users will need to obtain permission from the license holder to reproduce the material. To view a copy of this license, visit http://creativecommons.org/licenses/by/4.0/

(C) The Author(s) 2016 